\title{
Revisional bariatric surgery: a review of workup and management of common complications after bariatric surgery
}

\author{
Walker Lyons, Mennatallah Omar, Renee Tholey, Talar Tatarian \\ Division of Bariatric Surgery, Department of Surgery, Thomas Jefferson University Hospital, Philadelphia, PA 19107, USA. \\ Correspondence to: Dr. Talar Tatarian, Division of Bariatric Surgery, Department of Surgery, Thomas Jefferson University \\ Hospital, 211 S 9th Street, Suite 402, Philadelphia, PA 19107, USA. E-mail: talar.tatarian@jefferson.edu
}

How to cite this article: Lyons W, Omar M, Tholey R, Tatarian T. Revisional bariatric surgery: a review of workup and management of common complications after bariatric surgery. Mini-invasive Surg 2022;6:11. https://dx.doi.org/10.20517/25741225.2021 .140

Received: 19 Nov 2021 First Decision: 4 Jan 2022 Revised: 12 Jan 2022 Accepted: 19 Jan 2022 Published: 15 Feb 2022

Academic Editor: Giulio Belli Copy Editor: Yue-Yue Zhang Production Editor: Yue-Yue Zhang

\begin{abstract}
With the rising prevalence of obesity, there has been a steady rise in the number of bariatric surgeries performed worldwide. As expected, there has also been an increase in the number of revisional surgeries performed to manage acute and chronic postoperative complications. This review will discuss the major complications that can arise from the most common bariatric surgeries, their diagnosis, medical management, and potential revisional surgical options.
\end{abstract}

Keywords: Revisional bariatric surgery, bariatric surgery, bariatric complications, obesity

\section{INTRODUCTION}

Obesity continues to affect a significant percentage of the population worldwide, with estimates that $39 \%$ of the population is obese ${ }^{[1]}$. Bariatric surgery has long been proven to be a durable treatment for obesity and its related co-morbidities. The past two decades have seen an increase in the number of bariatric surgeries performed annually with a shift in surgical approach and the types of surgeries being performed $\mathrm{d}^{[2,3]}$. This large population of Americans now represents a unique group of patients with acute and chronic postoperative complications that require management. As such, there has also been an increase in revisional 
procedures, from approximately 9480 revisional bariatric surgeries in 2011 to 38,971 in $2018^{[2]}$. Herein, we review the major complications associated with the most common bariatric procedures: Laparoscopic Adjustable Gastric Banding (LAGB), Sleeve Gastrectomy (SG), Roux-en-Y Gastric Bypass (RYGB), Biliopancreatic Diversion with Duodenal Switch (BPD/DS), Single Anastomosis Duodeno-Ileal Bypass with Sleeve Gastrectomy (SADI-S) and potential revisional options for management.

\section{Nomenclature}

Before discussing options for revisional bariatric surgery, it is important to review the nomenclature and define the types of revisional surgery.

A conversion surgery is one that will anatomically change the index procedure to a different type of bariatric procedure, for example, converting a SG to a RYGB.

A corrective surgery fixes the complications or incomplete treatment effect of a prior bariatric procedure without converting to a different procedure type. This includes operative repair of leaks, fistulas, strictures, etc.

A reversal surgery restores the patient's original anatomy. Certain procedures cannot be reversed, for example, a SG.

\section{LAPAROSCOPIC ADJUSTABLE GASTRIC BANDING}

The number of LAGB performed in the United States has continued to decrease since its peak in 2008. This decline has been attributed to several factors, including increased utilization of SG, long-term data showing ineffective weight loss or weight regain with LAGB, and the complications of LAGB that will be touched on below. In 2018, LAGB made up only $1.1 \%$ of bariatric procedures performed in the United States ${ }^{[2]}$. While primary LAGB is rarely performed, providers still need to be comfortable with managing patients with LAGB and the complications that can arise. With any of the following complications, reversal to normal anatomy (removal of the band) is an acceptable option.

\section{Erosion}

The incidence of band erosion is between $0.6 \%-14.0 \%^{[4-7]}$. While the exact mechanism of erosion in LAGB is unclear, the risk remains as long as the device is implanted. The diagnosis can be difficult to elicit as patients often present with vague abdominal pain and weight regain. Some may develop cellulitis of the abdominal wall around the port. Rarely will patients present with acute perforation, pneumoperitoneum, and peritonitis. Endoscopy is the diagnostic tool of choice, and a portion or all of the band will be visualized within the lumen of the stomach. Treatment for band erosion is removal, with possible conversion to another procedure. Removal can be completed surgically (laparoscopic, robotic, or open), endoscopically, or some combination thereof. If conversion to another bariatric procedure is required for treatment of ongoing obesity and co-morbidities, it is typically delayed at least three months to allow for resolution of perigastric inflammation ${ }^{[4]}$.

\section{Slippage/prolapse}

Gastric band slippage or prolapse is when any portion of the stomach herniates under the band, resulting in an incorrectly positioned band. This often causes pouch dilation and leads to decreased weight loss, weight regain, severe gastroesophageal reflux disease (GERD), and even obstructive symptoms. The incidence of band slippage or gastric prolapse is between $0.4 \%-13.0 \%{ }^{[4,6,7]}$. While it can be seen on both abdominal radiograph and computerized tomography (CT) imaging, upper gastrointestinal (UGI) fluoroscopy 
confirms the diagnosis with contrast pooling into the excess prolapsed stomach. To help with diagnosis, the phi angle can be measured on abdominal radiography. The phi angle is measured between the longitudinal axis of the band and the spinal column. With normal gastric band positioning, the phi angle is typically between 4 and 58 degrees. An abnormal phi angle will be seen with malposition or slippage of the band (typically greater than 90 degrees) ${ }^{[6]}$.

The initial treatment after diagnosis should be band deflation. Ultimately, surgery will be required, which can be corrective with either band repositioning, band removal with or without replacement, or conversion to a different bariatric procedure ${ }^{[5]}$. Repositioning or rebuckling can be performed laparoscopically and involves unbuckling the band, reducing the herniated stomach, and then rebuckling the band in the proper position. This approach has a high rate of slippage recurrence ${ }^{[5]}$. Band removal with a replacement through a newly created retrogastric tunnel has better results and can be offered to patients who have had successful weight loss with LAGB. In cases when there is significant perigastric inflammation, this may need to be performed in two stages. In patients that have had ineffective weight loss or weight regain, conversion to a different bariatric procedure is recommended ${ }^{[8]}$.

\section{GERD}

While GERD is already more prevalent in morbidly obese individuals, LAGB can both exacerbate preoperative GERD and cause de novo GERD in approximately $33 \%$ of patients ${ }^{[5,9,10]}$. This carries with it the risk of ulcers, esophagitis, Barrett's esophagus, and malignancy. Initial treatment involves band deflation and initiation of acid suppression medications such as proton pump inhibitors (PPIs). If that is unsuccessful in treating symptoms or prevents effective weight loss, surgical intervention is warranted. Surgical options include reversal with band removal, correction with band repositioning, or conversion to RYGB. Repositioning is an option if the band is determined to be in a poor position, which often causes accompanying pouch dilation and GERD. If conversion is selected as the treatment option, conversion to RYGB is the surgery of choice as SG has been found to exacerbate or cause de novo GERD ${ }^{[10]}$.

\section{Weight regain/ineffective weight loss}

One of the main reasons for the decrease in LAGB performed over the last decade is the poor long-term weight loss results. At five years after surgery, approximately $40 \%$ of patients with LAGB will require another surgery for weight loss ${ }^{[11]}$. Similarly, at 7 years after surgery, only $43 \%$ of patients achieve $50 \%$ excess weight loss $(\% \mathrm{EWL})^{[7]}$. In a patient that presents with weight regain, the first step should be to confirm that the LAGB is functioning properly. Fluid should be aspirated from the band, and the system interrogated to ensure no leak is present. Next, the patient's diet should be carefully reviewed to see if lifestyle changes can be made to achieve better results. If weight regain or significant obesity still remain after both of these issues have been addressed, conversion to a different procedure should be discussed.

\section{Conversion from LAGB}

Conversion options from LAGB include SG, RYGB, and BPD/DS, though there is little data for conversion to $\mathrm{BPD} / \mathrm{DS}$. It should be noted that conversion to these procedures has higher complication rates than primary SG or RYGB. Additionally, there continues to be debate over-performing these procedures as a one- or two-stage operation. In one small study, leak rates for conversion to SG were $4.4 \%$ for one-stage and $0 \%$ for two-stage ${ }^{[12]}$. A more recent and larger study from Israel showed that complications rates, including leak, were similar for one- and two-stage procedures, though it should be noted that the two-stage procedure cohort had a higher BMI, more co-morbidities, and more prior non-bariatric abdominal surgeries ${ }^{[13]}$. A small, single-institution study showed that for RYGB, two-stage procedures had been shown a lower anastomotic stricture rate ${ }^{[14]}$. As band removal makes up approximately $27.6 \%$ of all revisional bariatric surgery, there has been an increasing trend towards performing conversions to SG or RYGB in a 
single stage $\mathrm{e}^{[2]}$.

\section{SLEEVE GASTRECTOMY}

SG has become the most commonly performed bariatric procedure in the United States since 2013 and represented $61.4 \%$ of all bariatric surgeries and $76.5 \%$ of primary bariatric surgeries in $2018^{[2]}$. This is attributed to excellent outcomes in weight loss and co-morbidity control with relatively low morbidity and mortality compared to other surgical options. Surgeons and their teams need to be familiar with the common complications that can arise after SG and the treatment options. Certain complications, such as leak and stricture, are more common after revisional SG than primary $S^{[15]}{ }^{[1}$. is important to note that for SG, reversal to normal anatomy is not an option.

\section{Leak}

Staple line leak is a rare but feared complication of SG as it can quickly lead to sepsis or the formation of a chronic gastric fistula. The incidence of leak after SG is around $1.5 \%$ but can range from $0.5 \%-5.8 \%{ }^{[4,16]}$. They most commonly occur near the gastroesophageal junction as a result of distal obstruction (narrowing, twisting) or ischemia. While there is no standardized definition, leaks can be classified by the timing of presentation: early (0-4 days), intermediate (5-9 days), or late ( $>10$ days). Patients will classically present with abdominal pain, fever, and sepsis. Early postoperative patients with persistent tachycardia, fever, and sudden changes in abdominal pain require a high clinical suspicion for the leak. Late leaks can present with a more insidious onset, but fever and abdominal pain are still the main symptoms. CT or UGI fluoroscopy are imaging modalities that can detect a leak and help guide management options.

The first tent of leak management is the treatment of sepsis with antibiotics, IV hydration, and source control. Depending on the timing of the leak, source control is typically obtained by percutaneous, endoscopic, or operatively placed drains. Patients with early leak and hemodynamic instability warrant an urgent return to the operating room for exploration, washout, drainage, and possible attempt at suture closure of the leak. There is some debate over the management of stable patients with early leaks. These patients can be taken to the operating room urgently for washout and drainage with the hope that tissue in the early stages of inflammation has a better chance of being oversewn ${ }^{[17]}$. Other studies point to similar leak and fistula treatment efficacy without operative intervention, instead managing these patients conservatively with percutaneous or endoscopic drainage and additional endoscopic interventions ${ }^{[18,19]}$. Stable patients with intermediate and late leaks are often managed conservatively with antibiotics and source control through percutaneous and/or endoscopic means. Regardless of the approach for leak management, the underlying cause of the leak must be addressed to allow for proper healing. For example, if there is evidence of distal obstruction at the incisura, this must be treated either surgically or endoscopically (i.e., gastropexy, stenting, balloon dilation, etc.). For a more in-depth review of endoscopic management of leak after sleeve gastrectomy, please refer to the article "Endoscopic Management of Early Complications Following Bariatric Surgery", found earlier in this issue.

The second tenet of leak management includes nil per os (NPO) and adequate nutritional support. The decision between enteral and parenteral nutrition is often intervention and surgeon specific. Some studies point towards earlier resolution of fistula in enterally fed patients and support routine creation of feeding gastrostomy or jejunostomy for patients who are taken to the operating room or placement of a nasojejunal feeding tube under endoscopic guidance ${ }^{[1,1,19]}$. Others support peripherally inserted central line placement with total parenteral nutrition, especially in patients who are managed fully endoscopically or percutaneously ${ }^{[20]}$. Ultimately, the decision on nutritional support is patient and surgeon specific and should depend on planned interventions, fistula size, and best estimates at the length of NPO status. 
The literature reports a wide range of times of fistula closure and the need for operative intervention. The average duration to the resolution of the leak is 40-61 days, with some data to suggest earlier resolution if operative intervention is more aggressively selected ${ }^{[17-19]}$. Rates for operative intervention for leak vary widely (27.4\%-61\%) and are often determined by surgeon preference for operative intervention or conservative management. Operative interventions include corrective surgeries such as washout and drainage with attempted suture closure. Due to the friability of the inflamed tissue at the leak site, suture closure has a high failure rate and often ends up requiring endoscopic interventions. Conversion to RYGB can also be performed as an initial treatment for the leak or as a later procedure in patients with a chronic fistula that has failed other treatment modalities ${ }^{[21]}$. Proximal leaks near the gastroesophageal junction have more difficulty healing and may require conversion to Roux-en-Y esophagojejunostomy, although another alternative is the creation of a Roux-en-Y fistulojejunostomy. In this technique, after debridement of the fistula margins, a Roux limb is fashioned to the fistula, followed by the creation of a jejunojejunostomy. This allows for the creation of a low-pressure system with a closed system for the leak ${ }^{[2]}$. Management options are complex, and the decision to abort continued endoscopic intervention in favor of revisional surgery should be discussed on a case-by-case basis with the involvement of a multidisciplinary team.

\section{Bleeding}

Bleeding after SG can be intraluminal or extraluminal and typically occurs in the acute postoperative period. Bleeding is usually found at the staple line but can also occur from the spleen, liver, short gastric vessels, sites of adhesiolysis or abdominal wall. Incidences of bleeding range from $0.6 \%-2.7 \%{ }^{[23,24]}$. Strategies to prevent staple line bleeding are outside the scope of this article. If there is a concern for bleeding, a physical exam and complete blood count are the main diagnostic tools. Once bleeding has been diagnosed, management will depend on the hemodynamic stability of the patient. Unstable patients should return to the operating room immediately for surgical control of the bleeding. Stable patients can typically be managed conservatively with fluid resuscitation, serial hemoglobin monitoring, and blood transfusion as needed. If the source is believed to be intraluminal, management should follow UGI bleeding protocol which can result in gastroscopy ${ }^{[25]}$. Extraluminal bleeding managed conservatively can result in hematoma formation, which may become infected, requiring percutaneous or surgical drainage ${ }^{[26]}$. Of note, bleeding after SG results in an increase in all complications, including readmission, reoperation, and 30-day mortality ${ }^{[23]}$.

\section{Stricture}

Stricture of the gastric sleeve can occur any time postoperatively with a reported incidence of $1.1 \%$ $3.5 \%{ }^{[2,27]}$. Patients can be asymptomatic or symptomatic. Symptomatic patients classically present with nausea, emesis, abdominal pain, and dysphagia. UGI fluoroscopy or endoscopy is the diagnostic tools of choice to identify the location (proximal or distal) and extent of stenosis. Stricture after SG is caused by either luminal narrowing or torsional scarring. These are often related to technical issues with the sleeve's creation: creating too narrow of a sleeve, poor staple alignment (especially over angulation at the incisura angularis), over-aggressive suturing of the staple line, or unintentional rotation of the staple line anteriorly to posteriorly. Stenosis can also develop as a byproduct of other complications such as leak. In symptomatic patients, endoscopic interventions are the cornerstone of treatment, including balloon or pneumatic dilation or stent placement. Endoscopic dilation has a success rate of $83.7 \%-90.7 \%$, with pneumatic dilation often being more successful than balloon dilation ${ }^{[27,28]}$. Typically, 1-6 endoscopic sessions are required. Placement of a self-expanding metal stent is used when dilation fails or if there is distal stenosis in the setting of a staple line leak ${ }^{[4,27,28]}$. If symptomatic stricture with obstruction persists, conversion to RYGB can be performed. 


\section{GERD}

De novo or exacerbation of pre-existing GERD has become the Achilles heel of SG. A recent systematic review and meta-analysis reports a $23 \%$ incidence of de novo GERD and a $6.8 \%$ long-term prevalence of Barrett's esophagus after $\mathrm{SG}^{[29]}$. This is likely caused by changes in pressure dynamics at the gastroesophageal junction with blunting or removal of the angle of His. Additionally, other complications such as leak or stricture can increase intragastric pressure, resulting in worsening reflux ${ }^{[4,30,31]}$. Workup of GERD post-SG is similar to patients without previous bariatric surgery and should include a thorough history, upper endoscopy, 24-h pH monitoring, barium swallow, and esophageal manometry. Special considerations include assessment for hiatal hernia $(\mathrm{HH})$ due to sleeve migration, retained or dilated gastric fundus, stricture formation, or severe angulation of the stomach at the incisura angularis. Initial treatment includes medical therapy with PPIs and close clinical follow-up with the assessment of symptoms and upper endoscopy. If treatment is refractory to medical management, surgical interventions can be offered. If there is an anatomical complication from the SG as listed above (i.e., distal stricture/angulation, $\mathrm{HH}$ ), corrective surgery can be considered. Otherwise, conversion to RYGB is generally the treatment of choice ${ }^{[31-33]}$.

\section{Hiatal hernia}

$\mathrm{HH}$ is often diagnosed pre- or intra-operatively and can play an important role in symptomatic GERD. Careful inspection of the esophageal hiatus is important to properly identify and repair a $\mathrm{HH}$ at the time of SG to decrease postoperative GERD ${ }^{[34,35]}$. HH can also present postoperatively with partial migration of the sleeve into the thoracic space. While some patients may be asymptomatic, others present with symptoms of reflux and dysphagia. This can be diagnosed with UGI fluoroscopy, CT scan, or upper endoscopy. Similar to a $\mathrm{HH}$ in a patient without a history of bariatric surgery, the patient's symptoms, degree of $\mathrm{HH}$, and response to medical therapy will guide the decision to operate. Operative management will depend on patient characteristics, particularly the need for additional weight loss or treatment of co-morbidities. If additional weight loss is not desired, a corrective hernia reduction and crural repair can be attempted. Otherwise, in the absence of contraindications, conversion to RYGB or DS can be considered ${ }^{[36,37]}$. Conversion is generally preferred as a creation of a gastrojejunostomy (in the case of RYGB) or duodeno-ileostomy (in the case of DS) can help anchor the stomach and prevent re-herniation.

\section{Weight regain/ineffective weight loss}

SG has gained popularity in part due to its success at long-term weight loss. A recent meta-analysis showed an average \%EWL of $58.3 \%$ after $\mathrm{SG}^{[38]}$. Another prospective study showed a decrease in BMI from $46.2 \mathrm{~kg} / \mathrm{m}^{2}$ to $30.5 \mathrm{~kg} / \mathrm{m}^{2}$ at 2 years and $32.9 \mathrm{~kg} / \mathrm{m}^{2}$ at 5 years $^{[39]}$. Weight regain after SG is difficult to measure because the definition of what constitutes weight regain is not uniform. Depending on the definition used, reported rates of weight regain range from $9 \%-91 \%{ }^{[40]}$. Until a consensus is achieved on a definition, it may be better to focus on the percentage of patients that have required conversion procedures for weight regain or ineffective weight loss; this ranges from $18 \%-36 \%^{[11,42]}$. Depending on the degree of weight loss desired and underlying co-morbidities or contra-indications, conversion to RYGB, BPD/DS, or SADI can be considered after an attempt at lifestyle modifications.

\section{ROUX-EN-Y GASTRIC BYPASS}

With the rising popularity of SG, RYGB accounts for approximately $17 \%$ of primary bariatric surgeries ${ }^{[2]}$. Comparatively, RYGB provides a greater \%EWL, and lower incidence of weight regain, especially in patients with higher $\mathrm{BMI}^{[42]}$. Conversely, RYGB is a longer and more technically complex operation with increased long-term morbidity ${ }^{[43]}$. Secondary RYGB procedures have even higher rates of complications as compared to primary RYGB or $\mathrm{SG}^{[44,45]}$. Unlike SG, reversal to normal anatomy is possible and will be addressed below. 


\section{Anastomotic leak}

Anastomotic leak after RYGB occurs most commonly at the gastrojejunostomy $(0.6 \%-1.6 \%)^{[43,46,47]}$ and less frequently the jejunojejunostomy $(0.2 \%)^{[48]}$. It typically presents in the first five days after surgery. Similar to staple line leak after SG, presenting symptoms include signs of intra-abdominal sepsis: fevers, tachycardia, and abdominal pain. UGI fluoroscopy or CT imaging is the diagnostic modality of choice. The tenets of management are similar to those described after SG, with a focus on sepsis management (IV hydration, antibiotics coverage, and source control) and nutritional support (NPO and enteral vs. parenteral nutrition). Depending on the timing and location of the anastomotic leak, intervention options include operative washout/drainage, anastomotic repair $v s$. revision, endoscopic drainage/stenting/repair, or percutaneous drainage.

Unlike a leak after SG, anastomotic leak after RYGB typically occurs earlier in the postoperative period and is, therefore, more often managed operatively. Additionally, it has a shorter time to healing with fewer endoscopic interventions ${ }^{[4]}$. Early postoperative leak and hemodynamic instability warrants an urgent return to the operating room for washout, drainage, and attempt at the closure of the leak. In the setting of the late postoperative leak or chronic fistula formation, endoscopic interventions should be attempted. A chronic leak at the gastrojejunostomy may require revision of the anastomosis or, as a last resort, conversion to an esophagojejunostomy. A leaking involving the jejunostomy is generally managed with a corrective revision of the anastomosis.

\section{Obstruction/internal hernia}

Early obstruction after RYGB (<30 days) occurs in $0.5 \%-1.7 \%$ of patients ${ }^{[50-52]}$, with an overall incidence around $3 \%-4.4 \%{ }^{[4-551,53-56]}$. The most common site of early obstruction is at the jejunojejunostomy, usually due to kinking or narrowing of the anastomosis. Other causes include intraluminal clot, internal hernia, incisional hernia, or distal adhesions. Adhesive disease and internal hernia are more likely to be the source of obstruction in late cases as compared to early, but obstruction at the jejunojejunostomy remains a significant contributor. Earlier studies show Roux limb obstruction from compression due to mesocolon scarring, but more recent studies show the incidence has decreased as retrocolic roux limb placement has decreased in practice ${ }^{[54,55]}$. Internal hernias still remain a significant cause of obstruction unique to RYGB, although some studies have shown a decreased incidence with the closure of mesenteric defects ${ }^{[57]}$.

CT with oral contrast is the diagnostic tool of choice. While obstructive symptoms may be similar to those found in non-bariatric patients, management differs in that a more aggressive surgical approach is required after RYGB. This is because internal hernias and closed-loop obstructions occur more frequently postRYGB, and the inability to decompress the biliopancreatic limb or gastric remnant with nasogastric tube increases the risk of ischemia and perforation ${ }^{[4]}$. With few exceptions, early obstruction after RYGB should prompt reoperation with increased urgency, particularly if there is a dilated biliopancreatic limb or gastric remnant. The type of corrective procedure will depend on the cause of the obstruction. Obstruction at the jejunojejunostomy may require takedown and revision of the anastomosis. Internal hernias should be reduced, bowel resected if non-viable, and defects closed if present. If there is significant dilation of the biliopancreatic limb or gastric remnant, placement of a decompressive gastrostomy tube within the gastric remnant should be considered ${ }^{[50,51]}$. Finally, there should be a low threshold to perform a diagnostic laparoscopy in patients with intermittent or chronic abdominal pain after RYGB, as internal herniation could be the underlying cause, even in the absence of CT findings.

\section{Bleeding}

Bleeding after RYGB typically occurs acutely after surgery $(<48 \mathrm{~h}$ ), while late bleeding ( $>30$ days) is usually caused by ulceration which will be covered in the next section. The incidence of bleeding after RYGB is 
between $1.5 \%-4.4 \%{ }^{[58-60]}$. Bleeding may be intraluminal at an anastomosis or can be intraabdominal from a staple line, port site, or site of adhesiolysis. The choice of diagnostic imaging should depend on the suspected site of bleeding and can include CT angiogram or endoscopy. In a stable patient, first-line treatment includes fluid resuscitation and blood transfusion as needed. Persistent anastomotic bleed may require endoscopic intervention (injection, clipping), though this may be challenging if bleeding is from the gastric remnant or jejunojejunostomy ${ }^{[1]]}$. Bleeding in an unstable patient requires emergent corrective surgery, either open or laparoscopic, to control the bleeding.

\section{Marginal ulceration}

Marginal ulcers (MU) are a well-documented complication following RYGB, with a reported incidence of around $6.5 \%$. However, depending on the specific definition used, rates range from $0.6 \%-16 \%{ }^{[4,62-64]}$. Risk factors include non-steroidal anti-inflammatory drug use, Helicobacter pylori infection, tobacco use, alcohol use, steroid use, large gastric pouch, gastrogastric fistula (GGF), and obstructing sleep apnea ${ }^{[65]}$. Symptoms of MU are similar to those of peptic ulcer disease and include epigastric pain, pyrosis, and nausea. Diagnosis is made with upper endoscopy, and unless treated, it can become a chronic problem causing bleeding, perforation, stricture, or fistula formation. First-line therapy for non-bleeding, non-perforated MU is medical treatment and risk factor modification. This includes the elimination of any potential risk factors such as non-steroidal anti-inflammatory drugs or tobacco, along with the initiation of acid suppression agents such as PPIs. Carafate and misoprostol have also been used in the treatment of MU. Endoscopy is used to follow the progression or resolution of MU.

If $\mathrm{MU}$ is refractory to medical management, surgical intervention is warranted. Corrective surgeries include resection and revision of the gastrojejunal anastomosis with excision of the ulcer. If a GGF is present, this must be resected as well. In severe refractory cases, RYGB reversal should be considered, especially in cases that have failed a prior corrective surgery ${ }^{[64]}$. Additionally, total gastrectomy with conversion to esophagojejunostomy can be performed ${ }^{[6]]}$.

Patients presenting with perforation of MU represent a surgical emergency, with a reported incidence of around $1 \%{ }^{[67]}$. Historically the corrective surgery of choice was exploratory laparotomy with washout out and revision of the gastrojejunostomy. There have since been several studies that have shown open or laparoscopic omental patch repair to be a safe and preferred corrective surgery with shorter operative times and hospital lengths of stay ${ }^{[6,696]}$. The decision to place a feeding tube within the remnant stomach or roux limb is at the surgeon's discretion. Once the patient has recovered from this acute event, medical management should be attempted, and if unsuccessful, corrective or reversal surgery can be considered.

\section{Gastrogastric fistula}

GGF between the gastric pouch and remnant stomach has a reported incidence between $1.2 \%-6.0 \% \%^{[4,70-72]}$. The incidence has decreased since surgical technical has changed from a non-divided to a transected gastric pouch when stapling. Some common symptoms include weight regain, epigastric pain, MU, and/or bleeding. It is unclear if MU contributes to GGF formation or vice versa, but the two are closely related. Patients with prior history of a gastric leak are more susceptible to GGF formation. Diagnosis can be made with UGI fluoroscopy, CT with oral contrast, or upper endoscopy ${ }^{[72]}$. GGF can also be an incidental finding in asymptomatic patients and can be observed with the caveat that there is a higher risk of MU formation, causing many to advocate for the initiation of PPI therapy. If symptomatic, medical management should be started based on the symptoms: pain control, antiemetics, antibiotics when there is a suspected infection, resuscitation if bleeding, PPIs and sucralfate if MU is present. Despite a small number of case reports that show resolution of GGF with medical management, surgery is likely needed to correct the problem. Endoscopic therapies have been attempted but have high failure rates and, even when successful, have high 
recurrence rates $^{[73]}$.

Corrective surgery is the definitive treatment option, but the specific procedure will vary based on the cause and location of the $\mathrm{GGF}^{[72]}$. GGF that are located near or directly involving the gastrojejunostomy often require resection and revision of the gastrojejunostomy along with GGF excision. If the GGF is located high on the gastric pouch, options include taking a sleeve of the gastric pouch to excise the GGF along with partial resection of the gastric remnant $v$ s. leaving the GGF on the remnant stomach and oversewing $\mathrm{it}^{[0,71,74]}$.

\section{GERD}

RYGB is the bariatric procedure of choice for those with pre-existing $\mathrm{GERD}^{[31-33]}$; however, a certain subset of patients may have persistent reflux symptoms. Potential mechanisms include large gastric pouch with acid hypersecretion, short roux limb with bile reflux, and HH. Workup is similar to GERD in the nonbariatric patient and should include upper endoscopy, $\mathrm{pH} /$ manometry, and UGI fluoroscopy. In patients that do not respond to medical therapy, surgical treatment should be tailored to the underlying cause (i.e., $\mathrm{HH}$ repair, pouch revision, roux limb lengthening). Additionally, there are some novel surgical options reported in small numbers ${ }^{[75]}$. These include modified fundoplication with a crural repair or magnetic sphincter augmentation using the LINX $^{\oplus}$ system $^{[6,77]}$.

\section{Malnutrition}

RYGB is a restrictive and malabsorptive surgery, so patients are at risk for malnutrition postoperatively. Incidences of malnutrition after RYGB are cited around $4.7 \%{ }^{[78]}$. Albumin and hemoglobin are often measured to detect malnutrition, but micronutrients are also at risk for a deficiency, including copper, magnesium, zinc, thiamine, folate, vitamin $\mathrm{B}_{12}$, vitamins $\mathrm{A}, \mathrm{D}, \mathrm{E}$, and iron ${ }^{[79,80]}$. For this reason, the lifelong monitoring of micronutrients is recommended. Iron deficiency anemia due to insufficient absorption can occur after RYGB and is more common in premenopausal females and patients with preoperative iron deficiencies. Iron supplementation is typically given after RYGB but continued monitoring of iron indices is important as supplemental dosage often needs to be increased, especially in high-risk patients ${ }^{[8]}$. While protein malnutrition has a much lower incidence than micronutrient deficiency, it can lead to the need for surgical correction. For severe protein malnutrition, one study showed success in treating with continuous nasal-jejunal tube feeds in combination with pancreatic enzyme supplementation. The duration of feeding lasts between 25-156 days ${ }^{[82]}$. While rare, patients suffering from malnutrition, usually in combination with other complications, may require reversal surgery ${ }^{[83]}$.

\section{Reversal of RYGB}

RYGB reversal is rare but can be indicated for certain complications. Zaveri et al. ${ }^{[84]}$ published a retrospective study of 50 patients who underwent reversal, the largest study to date. The most common indication for reversal was MU. Other indications include malnutrition, anatomic complications such as stricture or obstruction, and functional disorders such as chronic unexplained pain, intractable nausea and emesis, dumping syndrome, Roux limb stasis, or GERD with HH. The authors in this study describe resection of the gastrojejunostomy, mobilization of the proximal gastric remnant with resection of the fundus, creation of a gastrogastrostomy between the gastric pouch and remnant stomach, leaving the jejunojejunostomy intact, and excision of the Roux limb down to 15 to 20 centimeters to minimize bacterial overgrowth. Outcomes in the study had good success in eliminating the complications with acceptable morbidity ${ }^{[84]}$. Additionally, reversal to SG is a potential option to prevent associated weight regain. In these cases, after reversal to normal anatomy and creation of a gastrogastrostomy between the gastric pouch and gastric remnant, the gastric sleeve is fashioned. Two studies looking at these cases have found high complication rates, although Vilallonga et al..$^{[85]}$ and Carter et al ${ }^{[86]}$ improved their leak rate by plicating the middle part of the greater curvature instead of resecting it. 


\section{Weight regain/ineffective weight loss}

While RYGB is a successful and durable tool for weight loss, there remains a subset of patients who experience ineffective weight loss or weight regain. Weighted mean \%EWL after RYGB is around $67 \%$ two years after surgery but decreased to $52 \%$ after ten years ${ }^{[38]}$. This can be attributed to patient lifestyle, mental health, hormones, and technical consideration ${ }^{[8]}$. Upper endoscopy and UGI fluoroscopy should be performed to ensure there are no technically modifiable factors that are contributing to weight regain (i.e., GGF, large gastric pouch, dilated gastrojejunostomy). There have been many interventions described in the literature with varying degrees of success. Endoscopic procedures have shown limited success, as have operative banding of the gastric pouch ${ }^{[87,88]}$. Corrective surgical options include pouch resizing or revision of the gastrojejunostomy. RYGB distalization is another corrective option but does lead to an increased risk of malnutrition ${ }^{[87]}$. Two different techniques have been reported. The biliopancreatic limb can be distalized by dividing it close to the jejunojejunostomy and then moving it $75 \mathrm{~cm}$ proximal to the ileocecal value to create a very long roux $\operatorname{limb} b^{[89]}$. Alternatively, the roux limb can be distalized in a similar fashion by dividing it close to the jejunojejunostomy and moving it distally (with varying positions of reanastomosis suggested), which will create a long biliopancreatic $\operatorname{limb}^{[00-92]}$. Lastly, while technically demanding, conversion to $\mathrm{BPD} / \mathrm{DS}$ can be performed ${ }^{[4,88}$. This procedure can be done in one or two steps. A gastrogastrostomy is formed, followed by a sleeve gastrectomy as described in the RYGB reversal section. The duodenum is then transected $5 \mathrm{~cm}$ distal to the pylorus. The prior jejunojejunostomy is excised, and the old roux and biliopancreatic limbs are anastomosed in a side-to-side fashion. Measurements of the bowel should then be taken, and an appropriate length alimentary limb and common channel created (approximately 35\%-45\% and $8 \%-12 \%$ of total bowel, respectively $)^{[87]}$.

\section{BILIOPANCREATIC DIVERSION WITH DUODENAL SWITCH}

BPD/DS is the least commonly performed of the primary bariatric procedures. In 2018 , only $1 \%$ of the four primary bariatric procedures performed in the United States were BPD/DS ${ }^{[2]}$. Although infrequently performed, BPD/DS has the greatest \%EWL and resolution of obesity-related co-morbidities. Its lower prevalence is explained by the risk of malnutrition and long-term sequelae of malabsorption countered by the degree of weight loss desired. Complications, especially those requiring reoperation, are a key concern. Revision is most commonly due to excessive weight loss/malnutrition or inadequate weight loss. Reversal is usually due to malnutrition.

\section{Acute complications}

Early acute complications, such as leak or hemorrhage, are treated similarly to other bariatric operations. Appropriate management, surgical or nonsurgical, is dependent on hemodynamic stability, timing, and radiographic findings. Gastrointestinal leak is treated with stenting, percutaneous drainage, bowel rest, and parenteral nutrition. Bleeding is treated with blood transfusion and endoscopic therapy. Free leak, aggressive bleeding, or hemodynamic instability should prompt urgent surgical intervention.

\section{Malnutrition}

BPD/DS has both restrictive and malabsorptive components. Weight loss is secondary to malabsorption of nutrients rather than gastric restriction. The length of the common channel is proportional to the risk of nutritional deficiencies, malnutrition, and the risk of needing revision ${ }^{[33]}$. Nutritional complications, although common after BPD/DS, are often overlooked. It is important to recognize deficiencies early and aggressively treat them to prevent further complications. It is also important to note that deficiencies can develop years after surgery. 


\section{Changes in bowel habits}

After BPD/DS, patients may have increased bloating, flatulence, and loose stools. Excessive diarrhea is managed with dietary modification, antimotility agents, and pancreatic enzyme supplementation. Reversal or revision for excessive diarrhea is rare. Small intestinal bacterial overgrowth in the biliopancreatic limb is treated with metronidazole or rifaximin ${ }^{[94]}$.

\section{Protein malnutrition}

Of the patients undergoing BPD/DS, 30\% will have protein malnutrition in nine years ${ }^{[55]}$. Clinical and laboratory assessments (total protein, albumin, prealbumin) are used to diagnose protein-calorie malnutrition. For prevention, the recommended protein intake is $1.5-2.0 \mathrm{~g} / \mathrm{kg}$ body weight ${ }^{[94]}$. Treatment includes dietary counseling, nutritional supplements (enteral or parenteral), and, lastly, surgical intervention. Revision is attempted prior to reversal. Revision involves lengthening the common channel. Reversal is reserved for severe nutritional complications and non-compliant patients. Revision and reversal rates from excessive malabsorption ranges from $0.5 \%-4.9 \%$ and $0.2 \%-7 \%$, respectively ${ }^{[96]}$.

\section{Vitamin and micronutrient deficiencies}

After BPD/DS, patients are at considerable risk of developing vitamin and micronutrient deficiencies due to greater length of bypassed small intestine and duodenal exclusion. Fat-soluble vitamins, calcium, iron, zinc, and copper deficiencies have all been reported. After BPD/DS, iron deficiency and anemia occur in 8\%-62\% and $50 \%$ of patients, respectively ${ }^{[94]}$. Chronic calcium and vitamin D deficiency results in secondary hyperparathyroidism and accelerated bone turnover. Recommendations for screening and supplementation to prevent deficiency, as well as repletion of these deficiencies, are discussed in the American Society for Metabolic and Bariatric Surgery 2019 clinical practice guidelines ${ }^{[94]}$. The importance of lifelong monitoring and patient compliance cannot be overstated. Clinical evaluation and laboratory monitoring should be performed preoperatively and postoperatively after 3 months, 6 months, and then annually. If deficiencies are detected, repletion and more frequent assessment should be performed.

\section{Weight regain/ineffective weight loss}

BPD/DS is infrequently associated with ineffective weight loss. Revision for insufficient weight loss ranges from $0.5 \%-2.78 \%{ }^{[96]}$. Laparoscopic re-sleeve gastrectomy is recommended over shortening of the common channel ${ }^{[97]}$. Shortening of the common channel has shown unsatisfactory weight loss with an increased risk of nutritional complications ${ }^{[98]}$.

\section{SINGLE ANASTOMOSIS DUODENO-ILEAL BYPASS WITH SLEEVE GASTRECTOMY}

In 2020, SADI-S was endorsed by the American Society for Metabolic and Bariatric Surgery as an appropriate metabolic bariatric surgical procedure as a modification of the classic Roux-en-Y BPD/DS ${ }^{[99]}$. However, concerns remain over long-term nutritional sequelae, weight loss, and weight regain ${ }^{[99]}$. Although uncommon, predominant early complications include gastrointestinal leak, bleeding, and nausea. Longterm nutritional issues have been reported, including malnutrition, hypocalcemia, vitamin D deficiency, secondary hyperparathyroidism, and iron deficiency ${ }^{[100]}$. Like BPD/DS, close lifelong follow-up is essential.

\section{Conclusion}

With the rising prevalence of obesity, there has been a steady increase in the number of bariatric surgeries performed worldwide. As expected, there has also been an increase in the number of revisional surgeries performed to manage acute and chronic postoperative complications. Providers must be comfortable recognizing these complications and refer to bariatric specialists for appropriate workup and revisional surgery when indicated. 


\section{DECLARATIONS}

\section{Authors' contributions}

Researched and wrote all portions of manuscript except sections VI and VII, organized and formatted manuscript: Lyons W

Researched and wrote sections VI and VII: Omar M

Editing and research for sections VI and VII: Tholey R

Editing and research for entire manuscript: Tatarian $\mathrm{T}$

\section{Availability of data and materials}

Not applicable.

\section{Financial support and sponsorship}

None.

\section{Conflicts of interest}

All authors declared that there are no conflicts of interest.

\section{Ethical approval and consent to participate}

Not applicable.

\section{Consent for publication}

Not applicable.

\section{Copyright}

(c) The Author(s) 2022.

\section{REFERENCES}

1. Chooi YC, Ding C, Magkos F. The epidemiology of obesity. Metabolism 2019;92:6-10. DOI

2. English WJ, DeMaria EJ, Hutter MM, et al. American Society for Metabolic and Bariatric Surgery 2018 estimate of metabolic and bariatric procedures performed in the United States. Surg Obes Relat Dis 2020;16:457-63. DOI PubMed

3. Campos GM, Khoraki J, Browning MG, Pessoa BM, Mazzini GS, Wolfe L. Changes in utilization of bariatric surgery in the United States from 1993 to 2016. Ann Surg 2020;271:201-9. DOI PubMed

4. Brethauer SA, Kothari S, Sudan R, et al. Systematic review on reoperative bariatric surgery: American Society for Metabolic and Bariatric Surgery Revision Task Force. Surg Obes Relat Dis 2014;10:952-72. DOI PubMed

5. Snow JM, Severson PA. Complications of adjustable gastric banding. Surg Clin North Am 2011;91:1249-64, ix. DOI PubMed

6. Sonavane SK, Menias CO, Kantawala KP, et al. Laparoscopic adjustable gastric banding: what radiologists need to know. Radiographics 2012;32:1161-78. DOI PubMed

7. Suter M, Calmes JM, Paroz A, Giusti V. A 10-year experience with laparoscopic gastric banding for morbid obesity: high long-term complication and failure rates. Obes Surg 2006;16:829-35. DOI PubMed

8. te Riele WW, van Santvoort HC, Boerma D, van Westreenen HL, Wiezer MJ, van Ramshorst B. Rebanding for slippage after gastric banding: should we do it? Obes Surg 2014;24:588-93. DOI

9. Merrouche M, Sabaté JM, Jouet P, et al. Gastro-esophageal reflux and esophageal motility disorders in morbidly obese patients before and after bariatric surgery. Obes Surg 2007;17:894-900. DOI PubMed

10. Gutschow CA, Collet P, Prenzel K, Hölscher AH, Schneider PM. Long-term results and gastroesophageal reflux in a series of laparoscopic adjustable gastric banding. J Gastrointest Surg 2005;9:941-8. DOI PubMed

11. Kowalewski PK, Olszewski R, Kwiatkowski A, Gałązka-Świderek N, Cichoń K, Paśnik K. Life with a Gastric Band. Long-term outcomes of laparoscopic adjustable gastric banding-a retrospective study. Obes Surg 2017;27:1250-3. DOI PubMed PMC

12. Stroh C, Benedix D, Weiner R, et al; Obesity Surgery Working Group; Competence Network Obesity. Is a one-step sleeve gastrectomy indicated as a revision procedure after gastric banding? Obes Surg 2014;24:9-14. DOI PubMed

13. Perry Z, Romano-Zelekha O, Sakran N, et al. Laparoscopic sleeve gastrectomy following failed laparoscopic adjustable gastric banding - a comparison between one- and two-stage procedures, an Israeli National Database Study. Obes Surg 2021;31:2364-72. DOI PubMed

14. Van Nieuwenhove Y, Ceelen W, Van Renterghem K, Van de Putte D, Henckens T, Pattyn P. Conversion from band to bypass in two steps reduces the risk for anastomotic strictures. Obes Surg 2011;21:501-5. DOI PubMed

15. Coblijn UK, Verveld CJ, van Wagensveld BA, Lagarde SM. Laparoscopic Roux-en-Y gastric bypass or laparoscopic sleeve 
gastrectomy as revisional procedure after adjustable gastric band--a systematic review. Obes Surg 2013;23:1899-914. DOI PubMed

16. Gagner M, Kemmeter P. Comparison of laparoscopic sleeve gastrectomy leak rates in five staple-line reinforcement options: a systematic review. Surg Endosc 2020;34:396-407. DOI PubMed PMC

17. Abou Rached A, Basile M, El Masri H. Gastric leaks post sleeve gastrectomy: review of its prevention and management. World J Gastroenterol 2014;20:13904-10. DOI

18. Nimeri A, Ibrahim M, Maasher A, Al Hadad M. Management algorithm for leaks following laparoscopic sleeve gastrectomy. Obes Surg 2016;26:21-5. DOI PubMed

19. Bashah M, Khidir N, El-Matbouly M. Management of leak after sleeve gastrectomy: outcomes of 73 cases, treatment algorithm and predictors of resolution. Obes Surg 2020;30:515-20. DOI PubMed

20. Sakran N, Goitein D, Raziel A, et al. Gastric leaks after sleeve gastrectomy: a multicenter experience with 2,834 patients. Surg Endosc 2013;27:240-5. DOI PubMed

21. Degrandi O, Nedelcu A, Nedelcu M, Simon A, Collet D, Gronnier C. Roux-en-Y Gastric bypass for the treatment of leak following sleeve gastrectomy. Obes Surg 2021;31:79-83. DOI PubMed

22. Chouillard E, Chahine E, Schoucair N, et al. Roux-En-Y Fistulo-Jejunostomy as a salvage procedure in patients with post-sleeve gastrectomy fistula. Surg Endosc 2014;28:1954-60. DOI PubMed

23. Mocanu V, Dang J, Ladak F, Switzer N, Birch DW, Karmali S. Predictors and outcomes of bleed after sleeve gastrectomy: an analysis of the MBSAQIP data registry. Surg Obes Relat Dis 2019;15:1675-81. DOI PubMed

24. Gagner M, Deitel M, Kalberer TL, Erickson AL, Crosby RD. The second international consensus summit for sleeve gastrectomy, March 19-21, 2009. Surg Obes Relat Dis 2009;5:476-85. DOI PubMed

25. Sarkhosh K, Birch DW, Sharma A, Karmali S. Complications associated with laparoscopic sleeve gastrectomy for morbid obesity: a surgeon's guide. Can J Surg 2013;56:347-52. DOI PubMed PMC

26. De Angelis F, Abdelgawad M, Rizzello M, Mattia C, Silecchia G. Perioperative hemorrhagic complications after laparoscopic sleeve gastrectomy: four-year experience of a bariatric center of excellence. Surg Endosc 2017;31:3547-51. DOI PubMed

27. Turcu F, Balahura C, Doras I, Constantin A, Copaescu C. Symptomatic stenosis after laparoscopic sleeve gastrectomy - incidence and management in a high-volume bariatric surgery center. Chirurgia (Bucur) 2018;113:826-36. DOI PubMed

28. Mccarty TR, Thompson CC. How to manage sleeve complications through endoscopy: strictures. In: Al-sabah S, Aminian A, Angrisani L, Al Haddad E, Kow L, editors. Laparoscopic sleeve gastrectomy. Cham: Springer International Publishing; 2021. p. $477-$ 89. DOI

29. Yeung KTD, Penney N, Ashrafian L, Darzi A, Ashrafian H. Does sleeve gastrectomy expose the distal esophagus to severe reflux? Ann Surg 2020;271:257-65. DOI PubMed

30. Burgerhart JS, Schotborgh CA, Schoon EJ, et al. Effect of sleeve gastrectomy on gastroesophageal reflux. Obes Surg 2014;24:143641. DOI PubMed

31. Navarini D, Madalosso CAS, Tognon AP, Fornari F, Barão FR, Gurski RR. Predictive factors of gastroesophageal reflux disease in bariatric surgery: a controlled trial comparing sleeve gastrectomy with gastric bypass. Obes Surg 2020;30:1360-7. DOI PubMed

32. Madalosso CA, Gurski RR, Callegari-Jacques SM, Navarini D, Thiesen V, Fornari F. The impact of gastric bypass on gastroesophageal reflux disease in patients with morbid obesity: a prospective study based on the Montreal Consensus. Ann Surg 2010;251:244-8. DOI PubMed

33. Madalosso CA, Gurski RR, Callegari-Jacques SM, Navarini D, Mazzini G, Pereira Mda S. The impact of gastric bypass on gastroesophageal reflux disease in morbidly obese patients. Ann Surg 2016;263:110-6. DOI PubMed

34. Dakour Aridi HN, Tamim H, Mailhac A, Safadi BY. Concomitant hiatal hernia repair with laparoscopic sleeve gastrectomy is safe: analysis of the ACS-NSQIP database. Surg Obes Relat Dis 2017;13:379-84. DOI PubMed

35. Soricelli E, Iossa A, Casella G, Abbatini F, Calì B, Basso N. Sleeve gastrectomy and crural repair in obese patients with gastroesophageal reflux disease and/or hiatal hernia. Surg Obes Relat Dis 2013;9:356-61. DOI PubMed

36. Saba J, Bravo M, Rivas E, Fernández R, Pérez-Castilla A, Zajjur J. Incidence of de novo hiatal hernia after laparoscopic sleeve gastrectomy. Obes Surg 2020;30:3730-4. DOI PubMed

37. Felinska E, Billeter A, Nickel F, et al. Do we understand the pathophysiology of GERD after sleeve gastrectomy? Ann N Y Acad Sci 2020;1482:26-35. DOI PubMed

38. O'Brien PE, Hindle A, Brennan L, et al. Long-term outcomes after bariatric surgery: a systematic review and meta-analysis of weight loss at 10 or more years for all bariatric procedures and a single-centre review of 20-year outcomes after adjustable gastric banding. Obes Surg 2019;29:3-14. DOI PubMed PMC

39. Flølo TN, Andersen JR, Kolotkin RL, et al. Five-year outcomes after vertical sleeve gastrectomy for severe obesity: a prospective cohort study. Obes Surg 2017;27:1944-51. DOI PubMed

40. Lauti M, Lemanu D, Zeng ISL, Su'a B, Hill AG, MacCormick AD. Definition determines weight regain outcomes after sleeve gastrectomy. Surg Obes Relat Dis 2017;13:1123-9. DOI PubMed

41. Felsenreich DM, Langer FB, Kefurt R, et al. Weight loss, weight regain, and conversions to Roux-en-Y gastric bypass: 10-year results of laparoscopic sleeve gastrectomy. Surg Obes Relat Dis 2016;12:1655-62. DOI PubMed

42. Hauters P, Dubart JW, Desmet J, Degolla R, Roumain M, Malvaux P. Ten-year outcomes after primary vertical sleeve gastrectomy for morbid obesity: a monocentric cohort study. Surg Endosc 2021;35:6466-71. DOI PubMed

43. Kumar SB, Hamilton BC, Wood SG, Rogers SJ, Carter JT, Lin MY. Is laparoscopic sleeve gastrectomy safer than laparoscopic gastric bypass? Surg Obes Relat Dis 2018;14:264-9. DOI PubMed

44. Zhang L, Tan WH, Chang R, Eagon JC. Perioperative risk and complications of revisional bariatric surgery compared to primary 
Roux-en-Y gastric bypass. Surg Endosc 2015;29:1316-20. DOI PubMed

45. Mor A, Keenan E, Portenier D, Torquati A. Case-matched analysis comparing outcomes of revisional versus primary laparoscopic Roux-en-Y gastric bypass. Surg Endosc 2013;27:548-52. DOI PubMed

46. Mocanu V, Dang J, Ladak F, Switzer N, Birch DW, Karmali S. Predictors and outcomes of leak after Roux-en-Y gastric bypass: an analysis of the MBSAQIP data registry. Surg Obes Relat Dis 2019;15:396-403. DOI PubMed

47. Vidarsson B, Sundbom M, Edholm D. Incidence and treatment of leak at the gastrojejunostomy in Roux-en-Y gastric bypass: a cohort study of 40,844 patients. Surg Obes Relat Dis 2019;15:1075-9. DOI PubMed

48. Vidarsson B, Sundbom M, Edholm D. Incidence and treatment of small bowel leak after Roux-en-Y gastric bypass: a cohort study from the Scandinavian Obesity Surgery Registry. Surg Obes Relat Dis 2020;16:1005-10. DOI PubMed

49. Al-Kurd A, Grinbaum R, Abubeih A, et al. Not all leaks are created equal: a comparison between leaks after sleeve gastrectomy and Roux-En-Y Gastric bypass. Obes Surg 2018;28:3775-82. DOI PubMed

50. Shimizu H, Maia M, Kroh M, Schauer PR, Brethauer SA. Surgical management of early small bowel obstruction after laparoscopic Roux-en-Y gastric bypass. Surg Obes Relat Dis 2013;9:718-24. DOI PubMed

51. Khoraki J, Mazzini GS, Shah AS, Del Prado PAR, Wolfe LG, Campos GM. Early small bowel obstruction after laparoscopic gastric bypass: a surgical emergency. Surg Obes Relat Dis 2018;14:1118-25. DOI PubMed

52. Khrucharoen U, Juo YY, Wongpongsalee T, Chen Y, Dutson EP. Risk factors for readmission for early small bowel obstruction following laparoscopic Roux-en-Y gastric bypass: an MBSAQIP analysis. Surg Obes Relat Dis 2021;17:1041-8. DOI PubMed

53. Elms L, Moon RC, Varnadore S, Teixeira AF, Jawad MA. Causes of small bowel obstruction after Roux-en-Y gastric bypass: a review of 2,395 cases at a single institution. Surg Endosc 2014;28:1624-8. DOI PubMed

54. Hwang RF, Swartz DE, Felix EL. Causes of small bowel obstruction after laparoscopic gastric bypass. Surg Endosc 2004;18:1631-5. DOI PubMed

55. Husain S, Ahmed AR, Johnson J, Boss T, O'Malley W. Small-bowel obstruction after laparoscopic Roux-en-Y gastric bypass: etiology, diagnosis, and management. Arch Surg 2007;142:988-93. DOI PubMed

56. Gabrielli M, Jarry C, Hurtado S, et al. Small bowel obstruction following laparoscopic Roux-en-Y gastric bypass: is it always necessary to operate? Langenbecks Arch Surg 2021;406:1839-46. DOI PubMed

57. Amor IB, Kassir R, Debs T, et al. Impact of mesenteric defect closure during laparoscopic Roux-en-Y Gastric bypass (LRYGB): a retrospective study for a total of 2093 LRYGB. Obes Surg 2019;29:3342-7. DOI PubMed

58. Mehran A, Szomstein S, Zundel N, Rosenthal R. Management of acute bleeding after laparoscopic Roux-en-Y gastric bypass. Obes Surg 2003;13:842-7. DOI PubMed

59. Rabl C, Peeva S, Prado K, et al. Early and late abdominal bleeding after Roux-en-Y gastric bypass: sources and tailored therapeutic strategies. Obes Surg 2011;21:413-20. DOI PubMed

60. Zafar SN, Miller K, Felton J, Wise ES, Kligman M. Postoperative bleeding after laparoscopic Roux en Y gastric bypass: predictors and consequences. Surg Endosc 2019;33:272-80. DOI PubMed

61. Sundbom M, Nyman R, Hedenström H, Gustavsson S. Investigation of the excluded stomach after Roux-en-Y gastric bypass. Obes Surg 2001;11:25-7. DOI PubMed

62. Coblijn UK, Lagarde SM, de Castro SM, Kuiken SD, van Wagensveld BA. Symptomatic marginal ulcer disease after Roux-en-Y gastric bypass: incidence, risk factors and management. Obes Surg 2015;25:805-11. DOI PubMed

63. Pyke O, Yang J, Cohn T, et al. Marginal ulcer continues to be a major source of morbidity over time following gastric bypass. Surg Endosc 2019;33:3451-6. DOI PubMed

64. Di Palma A, Liu B, Maeda A, Anvari M, Jackson T, Okrainec A. Marginal ulceration following Roux-en-Y gastric bypass: risk factors for ulcer development, recurrence and need for revisional surgery. Surg Endosc 2021;35:2347-53. DOI PubMed

65. Rodrigo DC, Jill S, Daniel M, Kimberly C, Maher EC. Which factors correlate with marginal ulcer after surgery for obesity? Obes Surg 2020;30:4821-7. DOI PubMed

66. Chau E, Youn H, Ren-Fielding CJ, Fielding GA, Schwack BF, Kurian MS. Surgical management and outcomes of patients with marginal ulcer after Roux-en-Y gastric bypass. Surg Obes Relat Dis 2015;11:1071-5. DOI PubMed

67. Felix EL, Kettelle J, Mobley E, Swartz D. Perforated marginal ulcers after laparoscopic gastric bypass. Surg Endosc 2008;22:212832. DOI PubMed

68. Wendling MR, Linn JG, Keplinger KM, et al. Omental patch repair effectively treats perforated marginal ulcer following Roux-en-Y gastric bypass. Surg Endosc 2013;27:384-9. DOI PubMed

69. Wheeler AA, de la Torre RA, Fearing NM. Laparoscopic repair of perforated marginal ulcer following Roux-en-Y gastric bypass: a case series. J Laparoendosc Adv Surg Tech A 2011;21:57-60. DOI PubMed

70. Ribeiro-Parenti L, De Courville G, Daikha A, Arapis K, Chosidow D, Marmuse JP. Classification, surgical management and outcomes of patients with gastrogastric fistula after Roux-En-Y gastric bypass. Surg Obes Relat Dis 2017;13:243-8. DOI PubMed

71. Chahine E, Kassir R, Dirani M, Joumaa S, Debs T, Chouillard E. Surgical management of gastrogastric fistula after Roux-en-Y Gastric bypass: 10-year experience. Obes Surg 2018;28:939-44. DOI PubMed

72. Giambartolomei G, Menzo EL, Szomstein S, Rosenthal R. Gastro-Gastric Fistula Following Gastric Bypass. In: Camacho D, Zundel N, editors. Complications in Bariatric Surgery. Cham: Springer International Publishing; 2018. p. 85-99. DOI

73. Fernandez-Esparrach G, Lautz DB, Thompson CC. Endoscopic repair of gastrogastric fistula after Roux-en-Y gastric bypass: a lessinvasive approach. Surg Obes Relat Dis 2010;6:282-8. DOI PubMed

74. Corcelles R, Jamal MH, Daigle CR, Rogula T, Brethauer SA, Schauer PR. Surgical management of gastrogastric fistula. Surg Obes Relat Dis 2015;11:1227-32. DOI PubMed 
75. Suter M. Gastroesophageal reflux disease, obesity, and Roux-en-Y Gastric bypass: complex relationship-a narrative review. Obes Surg 2020;30:3178-87. DOI PubMed

76. Colpaert J, Horevoets J, Maes L, Uijtterhaegen G, Dillemans B. Surgical treatment of therapy-resistant reflux after Roux-en-Y gastric bypass. A case series of the modified Nissen fundoplication. Acta Chir Belg 2020;120:291-6. DOI PubMed

77. Broderick RC, Smith CD, Cheverie JN, et al. Magnetic sphincter augmentation: a viable rescue therapy for symptomatic reflux following bariatric surgery. Surg Endosc 2020;34:3211-5. DOI PubMed

78. Faintuch J, Matsuda M, Cruz ME, et al. Severe protein-calorie malnutrition after bariatric procedures. Obes Surg 2004;14:175-81. DOI PubMed

79. Dalcanale L, Oliveira CP, Faintuch J, et al. Long-term nutritional outcome after gastric bypass. Obes Surg 2010;20:181-7. DOI PubMed

80. Osland E, Powlesland H, Guthrie T, Lewis CA, Memon MA. Micronutrient management following bariatric surgery: the role of the dietitian in the postoperative period. Ann Transl Med 2020;8:S9. DOI PubMed PMC

81. Enani G, Bilgic E, Lebedeva E, Delisle M, Vergis A, Hardy K. The incidence of iron deficiency anemia post-Roux-en-Y gastric bypass and sleeve gastrectomy: a systematic review. Surg Endosc 2020;34:3002-10. DOI PubMed

82. Kuin C, den Ouden F, Brandts H, et al. Treatment of severe protein malnutrition after bariatric surgery. Obes Surg 2019;29:3095-102. DOI PubMed

83. Park JY, Kim YJ. Successful laparoscopic reversal of gastric bypass in a patient with malnutrition. Ann Surg Treat Res 2014;87:21721. DOI PubMed PMC

84. Zaveri H, Dallal RM, Cottam D, et al. Indications and operative outcomes of gastric bypass reversal. Obes Surg 2016;26:2285-90. DOI PubMed

85. Vilallonga R, van de Vrande S, Himpens J. Laparoscopic reversal of Roux-en-Y gastric bypass into normal anatomy with or without sleeve gastrectomy. Surg Endosc 2013;27:4640-8. DOI PubMed

86. Carter CO, Fernandez AZ, McNatt SS, Powell MS. Conversion from gastric bypass to sleeve gastrectomy for complications of gastric bypass. Surg Obes Relat Dis 2016;12:572-6. DOI PubMed

87. Maleckas A, Gudaitytė R, Petereit R, Venclauskas L, Veličkienė D. Weight regain after gastric bypass: etiology and treatment options. Gland Surg 2016;5:617-24. DOI PubMed PMC

88. Tran DD, Nwokeabia ID, Purnell S, et al. Revision of Roux-En-Y gastric bypass for weight regain: a systematic review of techniques and outcomes. Obes Surg 2016;26:1627-34. DOI PubMed

89. Brolin RE, Cody RP. Weight loss outcome of revisional bariatric operations varies according to the primary procedure. Ann Surg 2008;248:227-32. DOI PubMed

90. Rawlins ML, Teel D 2nd, Hedgcorth K, Maguire JP. Revision of Roux-en-Y gastric bypass to distal bypass for failed weight loss. Surg Obes Relat Dis 2011;7:45-9. DOI PubMed

91. Sugerman H. Conversion of proximal to distal gastric bypass for failed gastric bypass for superobesity. J Gastrointest Surg 1997;1:517-24. DOI PubMed

92. Fobi MA, Lee H, Igwe D Jr, et al. Revision of failed gastric bypass to distal Roux-en-Y gastric bypass: a review of 65 cases. Obes Surg 2001;11:190-5. DOI PubMed

93. Hamoui N, Chock B, Anthone GJ, Crookes PF. Revision of the duodenal switch: indications, technique, and outcomes. $J$ Am Coll Surg 2007;204:603-8. DOI PubMed

94. Mechanick JI, Apovian C, Brethauer S, et al. Clinical practice guidelines for the perioperative nutrition, metabolic, and nonsurgical support of patients undergoing bariatric procedures - 2019 update: cosponsored by American Association of Clinical Endocrinologists/American College of Endocrinology, The Obesity Society, American Society for Metabolic \& Bariatric Surgery, Obesity Medicine Association, and American Society of Anesthesiologists. Surg Obes Relat Dis 2020;16:175-247. DOI PubMed

95. Strain GW, Torghabeh MH, Gagner M, et al. Nutrient status 9 years after biliopancreatic diversion with duodenal switch (BPD/DS): an observational study. Obes Surg 2017;27:1709-18. DOI PubMed

96. Topart PA, Becouarn G. Revision and reversal after biliopancreatic diversion for excessive side effects or ineffective weight loss: a review of the current literature on indications and procedures. Surg Obes Relat Dis 2015;11:965-72. DOI PubMed

97. Gagner M. Laparoscopic revisional surgery after malabsorptive procedures in bariatric surgery, more specifically after duodenal switch. Surg Laparosc Endosc Percutan Tech 2010;20:344-7. DOI PubMed

98. Hess DS, Hess DW, Oakley RS. The biliopancreatic diversion with the duodenal switch: results beyond 10 years. Obes Surg 2005;15:408-16. DOI PubMed

99. Kallies K, Rogers AM; American Society for Metabolic and Bariatric Surgery Clinical Issues Committee. American Society for Metabolic and Bariatric Surgery updated statement on single-anastomosis duodenal switch. Surg Obes Relat Dis 2020;16:825-30. DOI PubMed

100. Brown WA, de Leon Ballesteros GP, Ooi G, et al; IFSO appointed task force reviewing the literature on SADI-S/OADS. Single Anastomosis Duodenal-Ileal Bypass with Sleeve Gastrectomy/One Anastomosis Duodenal Switch (SADI-S/OADS) IFSO position statement-update 2020. Obes Surg 2021;31:3-25. DOI PubMed 